\title{
Cultivo de la virtud: llamado en contra de la noción maquínica del ser humano propuesta por Félix Guattari
}

\author{
Virtue practice: called against the machinic notion of the \\ human being proposed by Félix Guattari
}

\section{Camila Alexsandra López Saavedra ${ }^{1^{*}}$ y Nevardo López Medina ${ }^{2}$.}

(1) Universidad Sergio Arboleda, Bogotá D.C. - Colombia, camila.alexsandra98@gmail.com

(2) Fundación Universitaria Juan de Castellanos, Tunja - Colombia, nlopezm@jdc.edu.co

* Autor a quien se dirige la correspondencia

"La verdad, desgarrando sus velos le devuelve a la unidad su origen, le reintegra.

Conocer es acordarse, y acordarse es reconocerse en lo que es, como siendo; es reconocerse en unidad. Conocer es desvanecer el velo del olvido, la sombra, para, en la luz, ser íntegramente" (Zambrano, 1987, p. 21).

\section{Resumen}

Félix Guattari considera que el ser humano es una máquina productora de deseos, lo cual, lleva a cuestionar si el ser humano es considerado como un instrumento para el logro de un fin, es decir, la revolución molecular. El presente trabajo propone el cultivo de la virtud como contraparte al deseo propuesto por F. Guattari, teniendo en cuenta el marco de la protesta social en Colombia porque este derecho, en tanto que, cuenta con derechos y deberes, su desconocimiento ha sido consecuencia de que se haya tergiversado la protesta como un conjunto de actos violentos que actúan en miras de un objetivo que no contribuye al bienestar del país, sino que altera el orden y la seguridad de este mismo.

Palabras clave: virtud; deseo; protesta social; Colombia.

\section{Abstract}

Félix Guattari considers that the human being is a machine that produces desires, which leads us to question whether the human being is considered as an instrument for the achievement of an end, that is, the molecular revolution. This paper proposes the cultivation of virtue as a counterpart to the desire proposed by F. Guattari, taking into account the framework of social protest in Colombia because this right, as it has rights and duties, its ignorance has been a consequence of the fact that protest has been misrepresented as a set of violent acts that act in pursuit of an objective that does not contribute to the welfare of the country, but it alters the order and security of it.

Keywords: virtue; desire; social protest; Colombia. 


\section{Introducción}

Concebir al ser humano como una máquina productora de deseos implica cuestionarse sobre cómo es vista la persona en el ámbito de lo social, ¿son los deseos de la persona, acaso, un instrumento para el logro de un fin que implica alterar el orden y la seguridad del país? Si bien, Félix Guattari considera que el ser humano es una máquina que es útil en tanto que está compuesta por diversas funciones, en especial, esta máquina es productora de deseos y, gracias a estos, se puede alcanzar la finalidad del logro de la revolución molecular (Guattari, 2013).

En el presente texto, no se pretende hablar de la revolución molecular en sí misma, sino de su elemento fundamental, es decir, el deseo y cómo guiar la voluntad por el deseo puede ser perjudicial para la persona y la sociedad; por esto, se propone la virtud como contraparte en la medida que su cultivo fortalezca los lazos de la comunidad y encamine las acciones, tanto para el bien particular como para el bien común.

En este orden, el presente trabajo se divide en tres partes: hacer una reflexión crítica del deseo y proponer la virtud como contraparte; dar a conocer qué es la protesta social, los deberes y derechos que de esta se desprenden y algunas leyes que indican cuándo la protesta no es legítima con sus respectivos ejemplos; finalmente, realizar las debidas inferencias en las que se concluya con un breve comentario a la protesta social en Colombia y cómo elegir el ejercicio de la virtud en vez del deseo podría repercutir en las acciones y elecciones de los ciudadanos desde su autonomía y reconocimiento de su dignidad.

\section{Reflexión crítica: virtud o deseo.}

Una oleada de inconformismo se hace visible en las calles, hay peticiones, reclamos y exigencias que se mueven, al parecer, en el hilo conductor del bien de la sociedad. Sin embargo, es necesario preguntar qué mueve a las personas de la sociedad civil a plantarse en contra de las decisiones de un gobierno; ¿hay, acaso, una coacción implícita, invisible que solo se desvela en la lectura entrelíneas respecto a las acciones de los seres humanos? No hay antídoto para el cese de la realidad que nos circunda, mas existe la posibilidad de analizarla y promulgar una serie de estrategias que abarquen el cúmulo de acciones que lleven al hallazgo de posibles causas de una problemática. Y la problemática que respecta a la creación de este texto es, cómo la concepción del ser humano como máquina deseante, propuesta por Félix Guattari, ha influido en las acciones humanas, en especial, en el modo en el que se ha llevado a cabo la protesta social en Colombia. 
•FIGURA 1•Problemática

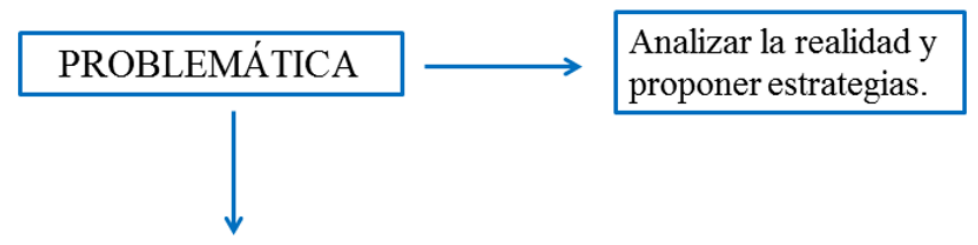

¿Cómo la concepción del ser humano como máquina deseante propuesta por Félix Guattari ha influido en las acciones humanas, en especial, en la Protesta Social en Colombia.

Fuente: elaboración propia

Sin embargo, antes de entrar a plantear escenarios que expliquen esta idea, es necesario partir de una breve reflexión que profundice las consecuencias de que el actuar humano esté influenciado por el deseo y, a su vez, una propuesta para saber cómo contratacar la afectación por el deseo. Y, para fomentar la curiosidad del lector esta propuesta solo será explicitada en la medida en que se desarrolle el presente texto.

No obstante, antes de comenzar, es preciso abordar una breve descripción del autor Félix Guattari para proceder al análisis de la noción de que el ser humano es una máquina productora de deseos. Félix Guattari (1930-1932) fue un filósofo, psicoanalista, activista político, fundador del análisis institucional y semiólogo. En sus inicios estuvo vinculado a Jacques Lacan, luego dejó el psicoanálisis por causa de su práctica en la clínica La Borde, fundada por Jean Oury en 1953. Fue un disidente, apartado de las estructuras tradicionales de la izquierda. Asimismo, participó junto con Giles Deleuze en la redacción de El AntiEdipo (1972); entre sus obras, se pueden mencionar La Revolución Molecular (1977) y Deseo y Revolución, diálogo con Paolo Bertetto y Franco Bifo Berardi (1977). Asimismo, es menester resaltar que a, quienes va dirigido el presente escrito, Revista Perspectivas en Inteligencia, podría no estar relacionada con el autor mencionado.

Cuando los seres humanos guían sus acciones por ciertos intereses superfluos, se evidencia que sus decisiones no obran en voluntad del bien común, sino de un interés, de cierto modo, egoísta. Así, las pasiones individuales se ponen por encima del bien de una comunidad. No obstante, si se siguen las palabras de Félix Guattari, es a partir del deseo que se logra la verdadera revolución y cuando este autor habla de revolución, hace un llamado a la micropolítica como fuente y mecanismo para cambiar el modelo de las instituciones, esto es, adentrarse al cambio radical de una sociedad, por medio, de la revolución molecular (Guattari, 2013). 
-FIGURA 2. Acciones guiadas por el deseo o el bien común

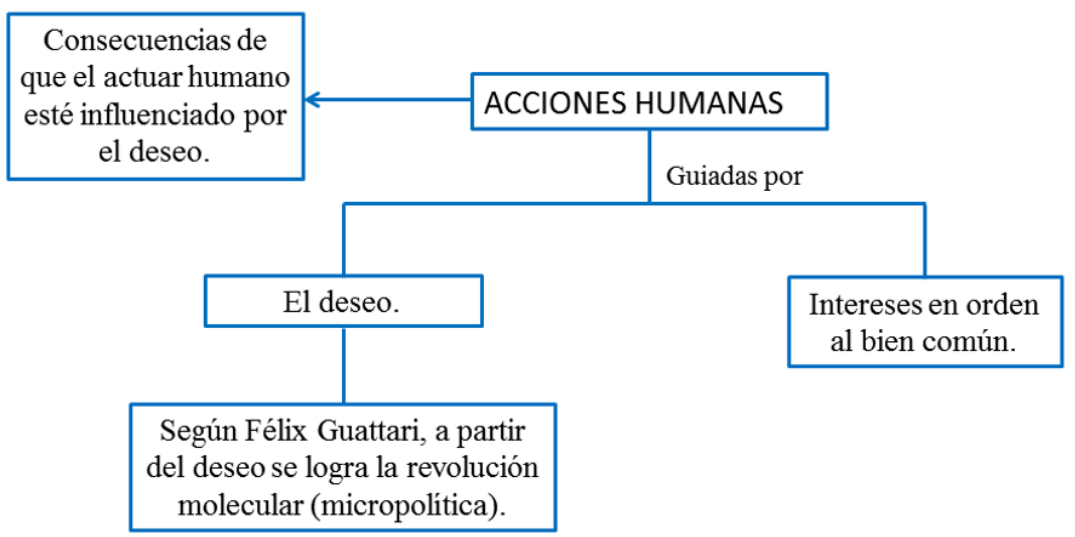

Fuente: elaboración propia

Por este motivo, es primordial enfocarse en uno de los ejes centrales del pensamiento de F. Guattari, la noción de que el ser humano es una máquina productora de deseos; esta premisa parece inocente, pero si se le llega a hacer un desglose, o mínimo análisis hermenéutico, se podrían descubrir los recovecos que guarda y las intenciones que oculta, es decir, una afirmación, como la que dice que el ser humano no es más que una máquina de deseos implica transformar la idea de que el ser humano no es un fin en sí mismo, sino un medio que produce deseos; por lo tanto, el ser humano pasa de ser causa de sí a convertirse en un medio maquínico. Lo cual, significa que la persona pierde su dignidad porque es vista como un conjunto de elementos y funciones útiles para una finalidad que constituye la revolución molecular.

Para continuar, Félix Guattari plantea que dicha revolución tendrá lugar por causa de la nueva sensibilidad de las personas (2013), dice que las relaciones interpersonales se han transformado; de cierta manera, enternece al ser humano, a partir de sus emociones que constituirían el origen de sus deseos. Así pues, con los avances de los Mass Media se ha hecho más fácil manipular a las masas y una de esas técnicas de manipulación reside en coaccionar a las personas por medio de sus emociones; por ejemplo, anuncios publicitarios que prometen una utopía como el ideal de cuerpo, tanto femenino como masculino, $y$, al visualizar esto una persona del común será guiada a desear este mismo ideal. Lo cual, desencadena una serie de acciones en vistas a la obtención de dicho deseo. 
-FIGURA 3• Ser humano: fin o medio

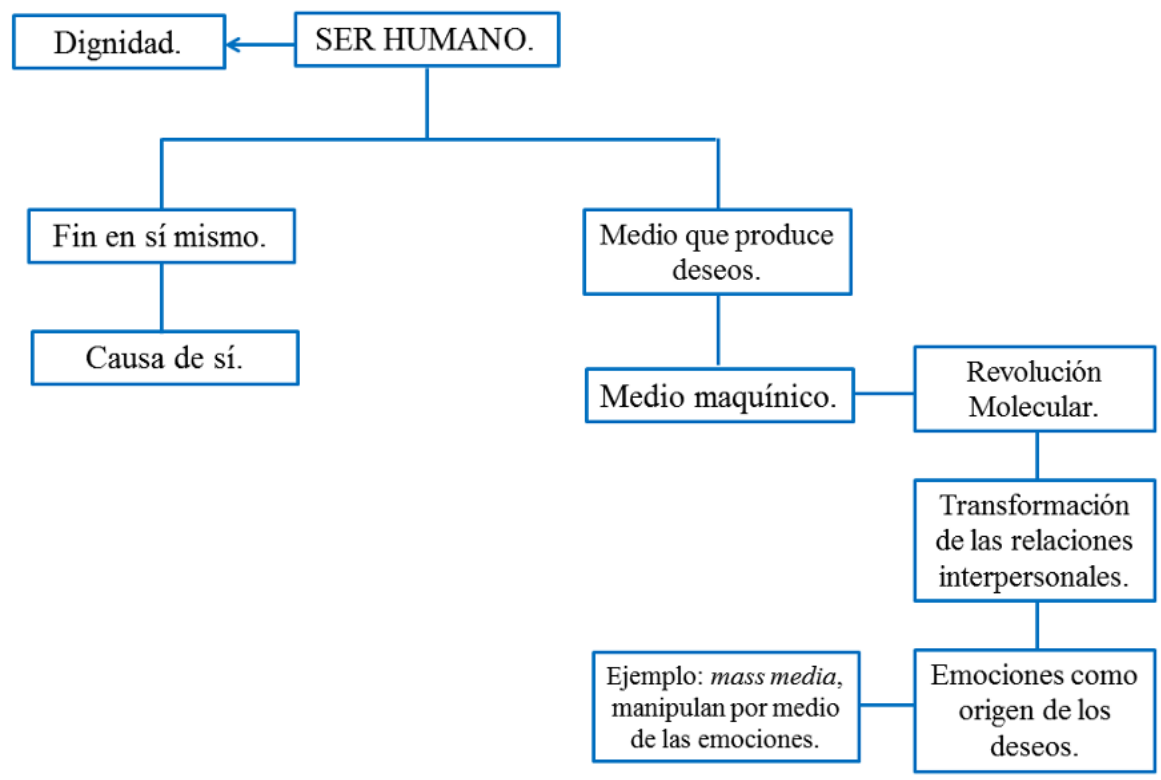

Fuente: elaboración propia

Según lo anterior, existen dos posibilidades: la consecución del deseo y la no consecución del deseo; ambas pueden generar ciertas consecuencias. Si la persona logra su deseo tendrá un sentimiento de afabilidad hasta que el deseo no le satisfaga o se desvanezca, o, si la persona no logra su deseo, sentirá enojo o tristeza, lo cual la llevaría a actuar violentamente, ¿por qué? Porque sus acciones están encaminadas, solo, a la satisfacción de ciertos deseos o intereses. En efecto, guiar la voluntad al logro de los deseos supone una pérdida de sentido en cuanto a la existencia humana, asimismo, la convivencia en una comunidad se pone en riesgo, se desvanece el sentido del honor, de la disciplina, entre otros. Pues, el ser humano para ser y no dejar de ser lo que es, siempre está haciendo algo, no es del todo pasivo, lo cual, no constituye una imposición, sino una elección voluntaria que se acoge bajo la responsabilidad de que el decidir es propio y nadie puede ocupar el lugar de las consecuencias de una decisión (Ortega y Gasset, 2016, p. 77).

En este sentido, los seres humanos que obran en miras del deseo es como si se encontraran en su propio reflejo y como Narciso se enamorasen de ellos mismos. Según Aristóteles, el placer se desencadena por las acciones de una persona movida por el deseo. Aquello que se hace por el deseo no puede ser involuntario, sino voluntario (2003, p. 42). Entonces, ¿cuál es el lugar del deber ser...? Y este deber ser no se extrae como una imposición, sino como un miramiento hacia el perfeccionamiento de las facultades humanas. El deseo es solo deseo, no implica perfeccionamiento sino satisfacción efímera que no enriquece la naturaleza humana, ni provee al bien individual ni al bien común. 
En la actualidad, impera la satisfacción del deseo sobre el perfeccionamiento práctico de la virtud. Mas, la dicha radica en la vida buena y en el obrar bien y la dicha o felicidad solo se puede hallar en el vivir bien conforme al ejercicio de la virtud (Aristóteles, 2003, p. 24). En tanto que, se pretende la plenitud al son de un chasquido. Las opiniones, palabra proveniente del griego doxa, son las nuevas verdades de una sociedad, verdades que conllevan al relativismo, por tanto, se evidencia el peligro que hay frente al olvido de la historia. Se busca crear nuevos estigmas culturales, nuevos mártires, ¿esto supondría una negación al pasado? Se ha llegado a infantilizar la historia. La historiografía es lo que es, en tanto que se puede analizar en retrospectiva, pero no negar, ni ocultar.

•FIGURA 4• Felicidad

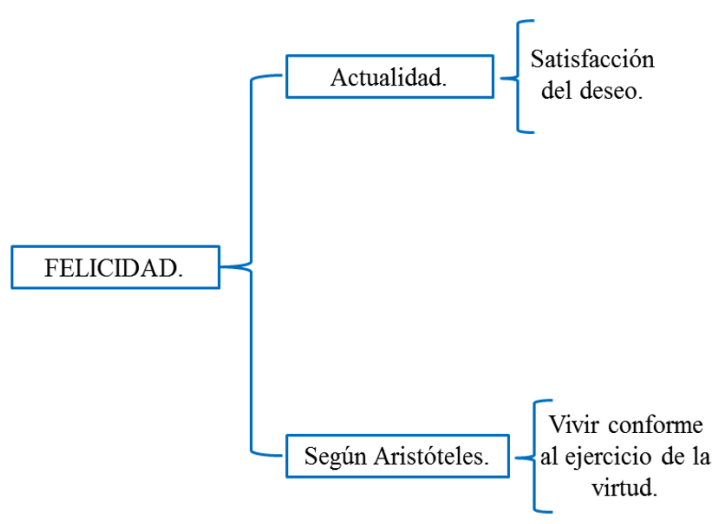

Fuente: elaboración propia

Es evidente, hoy día, la necesidad de enfocar la mirada de los ciudadanos. Existe un repiqueteo social que pide una nueva disposición al cultivo de los valores. La violencia, aunque no parece inteligente, es la nueva tendencia; hay una renuncia a la cultura que se orienta bajo normas y retrocede a una convivencia entre bárbaros. Se suprimen las reglas para ir directamente a imponer lo deseado (Ortega \& Gasset, 2010, p. 103). Hay un ciclo inconcluso de repetición, un eterno retorno, una destrucción entre personas que piensan diferente. Existe un recelo al hábito, a los valores, a la tradición, ¿por qué? Para responder, es necesario, recurrir a José Ortega \& Gasset:

El más y el menos de cultura se mide por la mayor o menor precisión de las normas. Donde hay poca, regulan éstas la vida sólo grosso modo; donde hay mucha, penetran hasta el detalle en el ejercicio de todas las actividades (Ortega \& Gasset, 2010, p. 100). 
-FIGURA 5•Causal de violencia

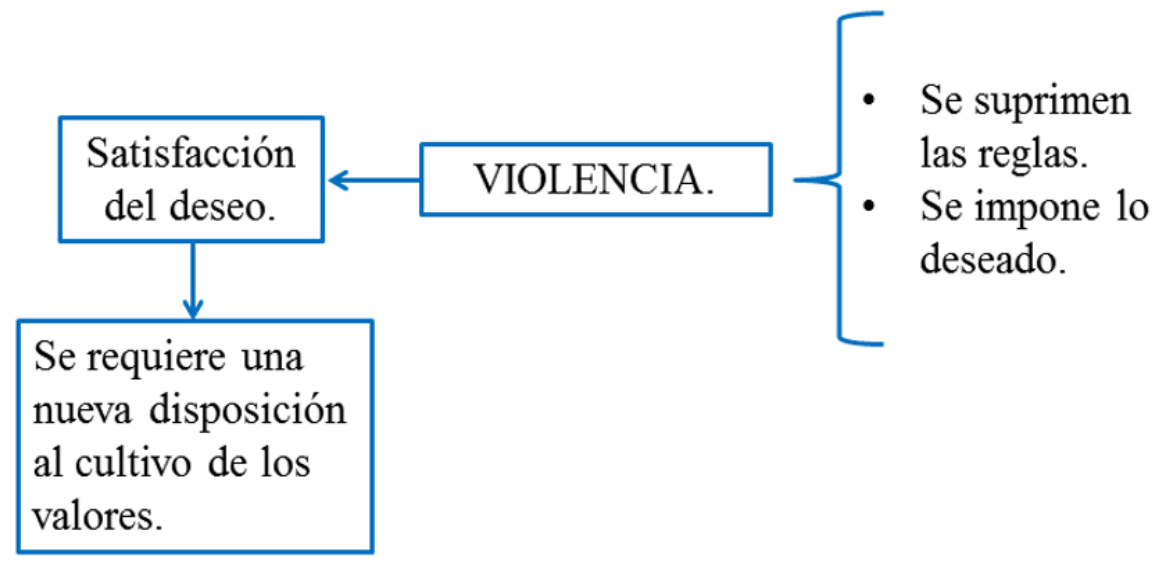

Fuente: elaboración propia

De este modo, cuál es la relación entre cultura y la concepción de las masas. Según Ortega \& Gasset, masa es quien es igual a todos, quien no cuenta con valor de sí, se da cuenta de ello y no le interesa; masa es quien se siente como todos y esto no le genera angustia (2010, p. 16). Las masas respectan no solo al ámbito de lo político, también a la vida cotidiana; por ejemplo, los lugares que antaño eran destinados a una minoría, están atestados por una multitud de personas que, ahora con el auge del capitalismo, tienen la posibilidad de ser partícipes de ciertos entornos que no estaban antes al alcance de todos (Ortega \& Gasset, 2010). En este caso, las minorías no son aquellos seres, supuestamente, honorables que sin haberse ganado el título nacieron en la cuna del honor heredado, es decir, son reconocidos en tanto que sus antecesores se ganaron por sus méritos tal reconocimiento; sino aquellos que enfocan sus acciones en el cultivo de su propio perfeccionamiento y son ellos mismos quienes por su mérito se diferencian de las masas aportando a la cultura, lo que enaltece el nombre propio, el de la familia y el de la patria.

Ahora bien, Ortega \& Gasset realiza una importante reflexión, el varón o mujer masa exigen unos derechos impersonales, exigen una libertad adusta en la ciega pretensión de que ser libre significa hacer lo que yo quiero, se sienten oprimidos, encarcelados, vulnerados (2010); sin embargo, ¿dónde se evidencia su lucha por ser mejores, de obrar en virtud al bien común? Parece que la consolidación de su sociedad ideal es una exigencia que no requiere esfuerzo, Ortega \&Gasset lo notó:

Eso era lo que antes acontecía, eso era la democracia liberal. La masa presumía que, al fin y al cabo, con todos sus defectos y lacras, las minorías de los políticos entendían un poco más de los problemas públicos que ella. Ahora, en cambio, cree la masa que tiene derecho a imponer y dar vigor de ley a sus tópicos de café. Yo dudo que haya habido otras épocas de la historia en que la muchedumbre llegase a gobernar tan directamente como en nuestro tiempo. Por eso hablo de hiperdemocracia (Ortega \& Gasset, 2010, p. 21). 
•FIGURA 6• Masa vs. Minoría

\begin{tabular}{|ll|}
\multicolumn{1}{|c|}{ MASA. } & \multicolumn{1}{c|}{ MINORÍA. } \\
\hline - Quien es igual a todos. & - Acciones enfocadas al propio \\
- Quien no cuenta con valor de & perfeccionamiento. \\
sí. & - Aportan a la cultura. \\
- Sabe que es igual y no le & - Enaltecen el nombre propio, \\
interesa. & de la familia y de la patria. \\
\hline
\end{tabular}

\section{Fuente: elaboración propia}

Nuestros antecesores, en su constante brío por mejorar la calidad de vida de las personas, generaron grandes obras y avances en los diversos ámbitos que constituyen la sociedad, ahora parece que todo está hecho, por esto exigimos (2010). Esta interpelación constituye implícitamente el obrar por el deseo, propuesto por Félix Guattari, en tanto nos sentimos decisores de la propia vida y del continuo fluir de una comunidad, imponemos ideales que en su propia subjetividad desestabilizan el orden $y$, es aún más peligroso, cuando dichos ideales son compartidos, ciegamente, por las masas.

La multitud opina cómo se debe gobernar, qué le conviene a una sociedad. Idealizamos un mundo en el que todos somos felices, dignos merecedores de ciertos privilegios, pero aparece el enojo cuando nos piden disciplina, respeto frente a la sabiduría de maestros, de padres, entre otros. Asimismo, surge el disgusto cuando nos piden sobriedad, recelo a los placeres que alteran nuestro estado de conciencia; si pensamos en ello, en efecto, nos hemos convertido en máquinas productoras de deseo. Así como planteó Aristóteles, aquel que no tenga dominio de sí, negará que sea responsable por su vicio, en el sentido de que, en el caso de que cometa una falta dirá que se vio tentado por el deseo. Lo cual, permite identificar cuándo se considera que hay violencia; hay violencia cuando la causa es exterior al sujeto que realiza la acción y no hay violencia cuando la causa es intrínseca al sujeto que obra (2003, p. 45).

-FIGURA 7• Obrar por el deseo o para mejorar la calidad de vida

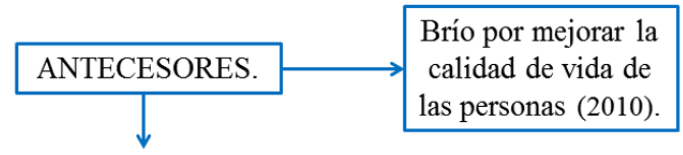

Obras y avances.

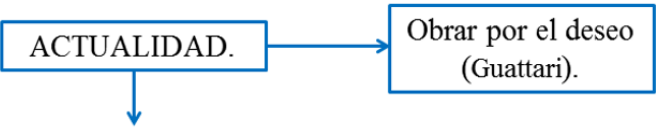

Se imponen ideales subjetivos que podrían desestabilizar el orden social.

Fuente: elaboración propia 
Por consiguiente, el ser humano se ha convertido, solo en un medio para el logro de ciertos ideales, que en este caso se ha de mencionar, uno de los que propone $\mathrm{F}$. Guattari, la destrucción de las instituciones (2013). El ser humano se ha convertido en un medio, un elemento más para generar la revolución molecular. El ser humano visto como máquina posee ciertas funciones útiles $\mathrm{y}$, si esa máquina no cumple con dichos elementos o funciones ¿quedará relegada al olvido? ¿Qué pasaría, por ejemplo, con personas de la tercera edad?.

Según Immanuel Kant, en la formulación del imperativo categórico se ve a la humanidad como fin en sí mismo, en lo cual, se entiende que todo individuo, en tanto que es autónomo no ha de ser coaccionado para el logro de cierto objetivo. "[...] el citado principio de autonomía es el único principio de la moral, pues de esa manera se halla que debe ser un imperativo categórico, que, no obstante, no manda ni más ni menos que esa autonomía justamente" (Kant, 2003, p. 98).

•FIGURA 8• El ser humano como medio maquínico o fin en sí mismo

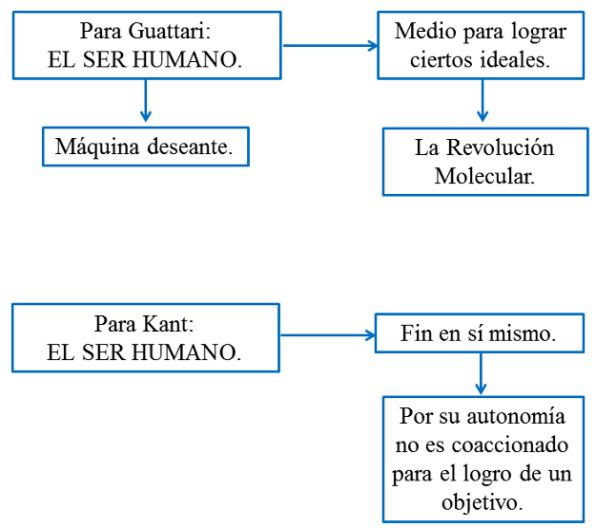

Fuente: elaboración propia

En efecto, valerse de las personas como medio, desencadena una notable instrumentalización humana en la que se pone en juego la libertad y dignidad humanas. A la hora en la que se instrumentaliza al ser humano se muestra una clara pérdida de valores, en la cual no importa arrasar con el bien común, mientras se logre un objetivo que podría desencadenar en terribles consecuencias para la persona, por ejemplo, un sujeto $\mathrm{x}$ quiere ascender a un puesto de mayor importancia en cierta empresa, para su logro al no tener suficientes méritos debe perjudicar a otros de los tres candidatos que, sin duda, cumplen con la formación y el mérito para el ascenso, utiliza estratagemas que vulneran a dichos sujetos y el sujeto $\mathrm{x}$, por tanto, logra el ascenso; cabe preguntar, ¿el sujeto x es digno para obtener el cargo? ¿Fueron válidas sus acciones, en tanto que logró el fin, pero mediatizó a tres sujetos para su consecución?. 
Hay quien nos finge perfectamente toda la mise en scène del dolor de muelas sin padecerlo, para justificar fines privados. Ya veremos cómo, en cambio, la vida de cada cual no tolera ficciones, porque al fingirnos algo a nosotros mismos sabemos, claro está, que fingimos y nuestra íntima ficción no logra nunca constituirse plenamente, sino que en el fondo, notamos su inautenticidad, no conseguimos engañarnos del todo, y le vemos la trampa (Ortega y Gasset, 2016, p. 73).

Son cuestiones que es necesario tener en cuenta para que más adelante en el desarrollo del presente texto, sea posible hacer un paralelo entre lo expuesto hasta ahora y la protesta social. De esta manera, se intentará responder ¿cómo se puede relacionar la noción de humanidad como fin en sí mismo y el cultivo de la virtud como contraparte del deseo en el marco de la protesta social? Para ello, se debe partir de un concepto de protesta social, los derechos y deberes que se desprenden del derecho a la protesta social y, finalmente, Leyes y ejemplos de noticias del marco nacional que validen el objetivo que se menciona.

Por consiguiente, antes de continuar con este discurso, es necesario hacer un breve esquema de lo expuesto hasta ahora para evitar confusiones o malentendidos. Así pues, la afirmación de Félix Guattari en la que defiende que los seres humanos son máquinas productoras de deseo desencadena ciertas incógnitas que ponen en duda la concepción de humanidad porque se integra un medio o disposición maquínica al funcionamiento humano, lo cual, indica que la percepción, tanto de hombres como mujeres, se mediatiza para la consecución de la revolución molecular como finalidad que utiliza a la máquina productora de deseos: el ser humano, para la destrucción y pronta transformación de las instituciones desde el marco de lo molecular.

De igual manera, se enternecen, con Félix Guattari, las emociones humanas o lo que este mismo autor llama, la nueva sensibilidad (Guattari, 2013), que es medio fundamental para la coacción de las masas. Frente a esto, se propone una percepción que ha existido, a lo largo del tiempo, esta es el cultivo de la virtud como manera de que el ser humano, por medio del esfuerzo y la entrega se convierta en lo que debe ser porque no siempre hemos de ligar la libertad como una actuación deliberada sin consecuencias, sino como un deber ser dispuesto al servicio de la comunidad.

Puesto que, el honor se forja con las batallas que la vida asigna, no con los deseos descarrilados que el individuo impone a la realidad; "[...] todas las complacencias y enojos, todos los deseos y repulsiones están motivados por valores, pero estos no valen porque nos agraden o los deseemos, sino al revés, nos agradan y los deseamos porque nos parece que valen" (Ortega y Gasset, 2013, p. 26). De esto, se sobreviene la importancia de tratar al ser humano como fin en sí mismo, con su autonomía y dignidad propias que como ser humano íntegro le conciernen. 
-FIGURA 9• Propuesta: cultivo de la virtud

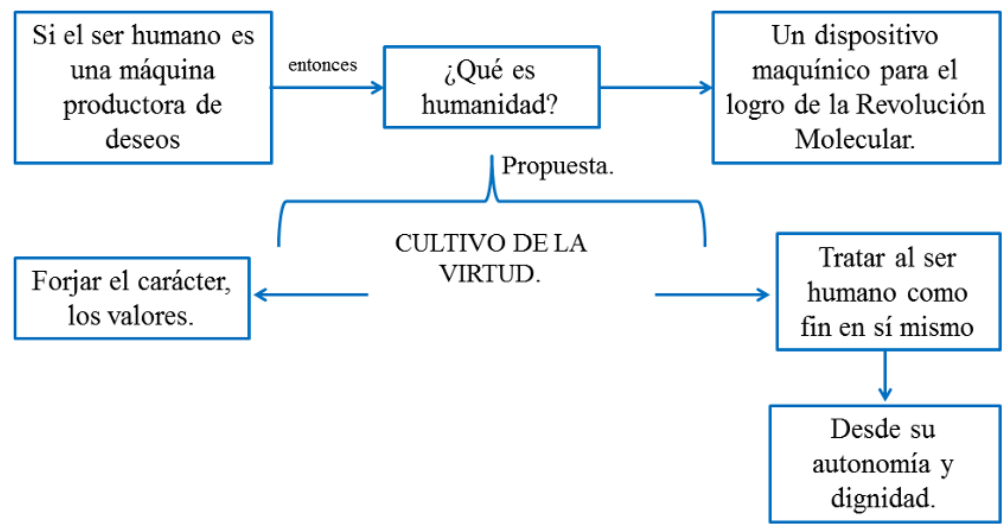

Fuente: elaboración propia

\section{Abuso por desconocimiento: La Protesta Social.}

La protesta social como derecho humano está protegida por instituciones internacionales, por la ley y por la Constitución Política de Colombia y se relaciona con los siguientes derechos fundamentales: la libertad de expresión, la libre reunión, huelga y participación; también, es considerada como un medio del que se valen los ciudadanos para reivindicar sus derechos que como tal les pertenecen. La protesta social, por su parte, ha de ser pacífica desarrollándose de manera individual o colectiva. Así como no se puede impedir la actividad de este derecho, tampoco se puede imponer su participación. Y deja de ser legítima cuando se recurre a narrativas de violencia, odio e intolerancia que promulgue la guerra o ponga en riesgo la seguridad del país. (Defensoría del Pueblo, 2020).

La protesta social, dado que, es un derecho que legítimamente está protegido por la Constitución Política de Colombia en el artículo 37: “Toda parte del pueblo puede reunirse y manifestarse pública y pacíficamente. Sólo la ley podrá establecer de manera expresa los casos en los cuales se podrá limitar el ejercicio de este derecho" (1991). En efecto, la ciudadanía en el ámbito de la protesta social, cuenta con derechos y/o privilegios y, a su vez, ha de cumplir con deberes. 
-FIGURA 10• ¿Qué es la protesta social?

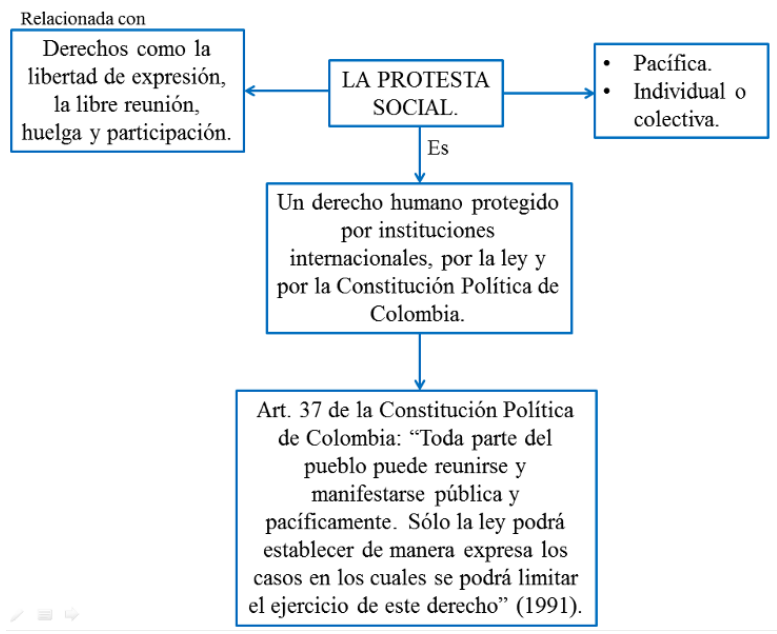

Fuente: elaboración propia

De esta manera, los derechos con los que cuenta la ciudadanía son: manifestación y reunión en lugares públicos para exponer intereses colectivos, movilización social como forma de incidir en asuntos de interés público o político, libre elección respecto a la forma y el mensaje de la protesta, mantener informadas a las autoridades acerca de la realización de la protesta para proteger los derechos y la seguridad de los ciudadanos colombianos (tanto de quienes participan como de quienes no lo hacen), gestión del conflicto desde el diálogo por parte del Estado e imputar acción de tutela en el caso de que se vulnere el derecho a la protesta (Defensoría del pueblo, 2020, p. 13).

Es menester recordar que la ciudadanía colombiana cuenta con el derecho a la protesta social, mientras sea pacífica y no vulnere los derechos de los individuos que no sean actores de este ejercicio, propio, de la democracia participativa. Es imprescindible que los ciudadanos desarrollen su derecho desde el conocimiento de lo que pueden hacer y lo que deben cumplir. Por esto, ya mencionados los derechos, es menester dar a conocer los deberes que beben cumplir los ciudadanos en el marco de la protesta social: entender que en la actividad de la protesta pacífica se cuenta con deberes y responsabilidades, solo la protesta que es pacífica es protegida por la ley, conocer el motivo de la protesta, saber cuáles serán las actividades de la movilización, el sujeto debe informar a familiares o amigos que va a participar en la movilización, tener claridad de su actuación por si llegan a surgir enfrentamientos con las autoridades o con grupos infiltrados que hayan organizado contratiempos y tener claros los derechos y deberes en el momento de participar en la protesta pacífica (Defensoría del pueblo, 2020, p. 15). 
-FIGURA 11• Algunos derechos y deberes en la protesta

\begin{tabular}{|c|c|}
\hline \multicolumn{2}{|c|}{$\begin{array}{l}\text { ALGUNOS DERECHOS Y DEBERES DE LOS } \\
\text { CIUDADANOS EN LA PROTESTA SOCIAL EN } \\
\text { COLOMBIA. }\end{array}$} \\
\hline DERECHOS & DEBERES \\
\hline $\begin{array}{l}\text { Reunión en lugares } \\
\text { públicos para exponer } \\
\text { intereses colectivos. } \\
\text { - Movilización social como } \\
\text { forma de incidir en asuntos } \\
\text { de interés público o } \\
\text { político. } \\
\text { - Libre elección respecto a la } \\
\text { forma y el mensaje de la } \\
\text { protesta. } \\
\text { Mantener informadas a las } \\
\text { autoridades acercade la } \\
\text { realización de la protesta } \\
\text { para proteger los derechosy } \\
\text { la seguridad de los } \\
\text { ciudadanos. }\end{array}$ & $\begin{array}{l}\text { - La protesta que es pacífica } \\
\text { es protegida por la ley. } \\
\text { - Conocer el motivo de la } \\
\text { protesta. } \\
\text { - Saber cuáles serán las } \\
\text { actividades de la } \\
\text { movilización. } \\
\text { - Tener claridad de su } \\
\text { actuación por si llegan a } \\
\text { surgir enfrentamientos con } \\
\text { las autoridades o con } \\
\text { grupos infiltrados que } \\
\text { hayan organizado } \\
\text { contratiempos. } \\
\text { (Defensoria del pueblo, 2020). }\end{array}$ \\
\hline
\end{tabular}

Fuente: elaboración propia

Asimismo, quienes participan de la protesta y las autoridades que velan por el orden de la misma deben cumplir con ciertas normativas para garantizar la protección legítima y el orden durante y después de la protesta pacífica; por un lado, los deberes que deben cumplir quienes participan en la protesta social son: ejercer el derecho de libre expresión conlleva el deber de respetar los derechos y la dignidad de los otros, no hacer propaganda que indique ofensiva o apología al odio que induzca a la violencia, no violentar a un servidor público, no imposibilitar el servicio de transporte público o la libre circulación de este; por otro lado, a las autoridades se les prohíbe criminalizar la protesta social pacífica, emitir falsos mensajes sobre quienes invitan y participan en las movilizaciones, realizar señalamientos falsos entre la relación manifestantes y grupos armados al margen de la ley o la deslegitimación del derecho a la protesta, limitar la libertad de expresión con la excusa de que se aplican medidas para la seguridad nacional, responsabilizar a los manifestantes por el mal comportamiento de otras personas, confiar el orden público a los convocantes de las manifestaciones (Defensoría del Pueblo, 2020, p. 21).

-FIGURA 12. Deberes de los participantes y las autoridades en la protesta

\begin{tabular}{|c|c|}
\hline \multicolumn{2}{|c|}{$\begin{array}{l}\text { ALGUNOS DERECHOS Y DEBERES DE LOS } \\
\text { CIUDADANOS EN LA PROTESTA SOCIAL EN } \\
\text { COLOMBIA. }\end{array}$} \\
\hline DERECHOS & DEBERES \\
\hline $\begin{array}{l}\text { - Reunión en lugares } \\
\text { públicos para exponer } \\
\text { intereses colectivos. } \\
\text { - Movilización social como } \\
\text { forma de incidir en asuntos } \\
\text { de interés público o } \\
\text { politico. } \\
\text { - Libre elección respecto a la } \\
\text { forma y el mensaje de la } \\
\text { protesta. } \\
\text { - Mantener informadas a las } \\
\text { autoridades acercade la } \\
\text { realización de la protesta } \\
\text { paraproteger los derechosy } \\
\text { la seguridad de los } \\
\text { ciudadanos. }\end{array}$ & $\begin{array}{l}\text { - La protesta que es pacíica } \\
\text { es protegida por la ley. } \\
\text { - Conocer el motivo de la } \\
\text { protesta. } \\
\text { - Saber cuáles serán las } \\
\text { actividades de la } \\
\text { movilización. } \\
\text { - Tener claridad de su } \\
\text { actuación por si llegan a } \\
\text { surgir enfrentamientos con } \\
\text { las autoridades o con } \\
\text { grupos infiltrados que } \\
\text { hayan organizado } \\
\text { contratiempos. } \\
\text { (Defensoria del pueblo, 2020). }\end{array}$ \\
\hline
\end{tabular}

Fuente: elaboración propia 
Aunque la protesta social es un derecho y quienes participan de esta lo hacen para reivindicar derechos o dar a conocer alguna encomienda o insatisfacción, ha sido también un instrumento para desvirtuar la realidad social y para hacer perder credibilidad al Estado y sus organismos de seguridad. El Ex-ministro de Defensa, Guillermo Botero, manifestó que en algunos territorios los grupos armados al margen de la ley son precursores y causales de las manifestaciones, lo cual genera rechazo a la protesta social ya que se considera que esta ha sido instrumentalizada para el logro de un sinnúmero de intereses propios (Fundación Ideas para la Paz, 2018, p. 4).

Es conveniente prestar atención a lo siguiente: pese a que la protesta social está protegida e identificada con derechos fundamentales ya mencionados, se evidencia que, en algunos casos, se ha acometido la protesta social en contra de la seguridad del país o de los organismos del Estado, en tanto que se muestra la falta de pacifismo, violencia e intereses adversos que demuestran que la actividad, en la cual se lleva a cabo la protesta social está perdiendo su objetivo intrínseco: el hacer valer los derechos o exigir beneficios que como ciudadanos promulgan. Hechos que hoy día son latentes y siguiendo el marco de ciertos parámetros legales se está injuriando el respectivo derecho a la protesta social pacífica.

Durante el momento en el que se ejerce el derecho a la protesta social, los ciudadanos y las autoridades deben tener en cuenta los deberes y derechos con los que deben cumplir, y hacer valer para reconocer los beneficios legales de los cuales pueden gozar por causa de la protesta pacífica, en efecto, se han logrado importantes avances en el ámbito de lo social y lo educativo.

No obstante, se ha tergiversado lo que significa la protesta en Colombia; por ejemplo, durante enero del 2016 hubo protestas contra las políticas de Juan Manuel Santos, Colombia Legal Corporation comenta que días anteriores al 21 de enero, la Policía Nacional en Bogotá contuvo a un buen número de personas porque impedían el libre movimiento de buses en el Transmilenio. Los individuos consideraron que se estaba impidiendo el libre ejercicio de su derecho a la protesta, mas no dieron cuenta de que dicha acción era una consecuencia del desconocimiento de lo que significa protestar en Colombia (Redacción Editorial, 2016). La protesta de los ciudadanos debe ser pacífica, pero, por intereses de terceros se da a conocer de una manera adversa. Otro ejemplo que se puede mencionar es la noticia del 29 de enero de 2013, en la cual se plantea que no se viola el derecho a la protesta cuando se sanciona a personas que obstruyen o no permiten el transporte en la vía pública (Legis, 2013).

Según lo anterior, es menester recordar lo que dice el artículo 353 y $353^{\text {a }}$ de la ley 1453 de 2011 que consiste en que la detención es legal cuando se obstaculizan las vías públicas, en donde se altera el orden y se obstruye el paso a las vías nacionales y el transporte; lo cual, indica que se afectan derechos como la seguridad alimentaria, el derecho al trabajo y se pone en riesgo la seguridad de terceros (Congreso de la República, 2011). Otros casos en los que la Ley tiene la potestad de limitar el ejercicio del derecho a la protesta se expone en el artículo 469 de la Ley 1453 de 2011, afirma que es punible valerse de la violencia o el uso de armas cuando se hace algún reclamo a la autoridad (Congreso de la República, 2011). En efecto, la ley 1453 de 2011 conocida 
como la ley de seguridad ciudadana surge con el fin de eliminar la impunidad, ir en contra del terrorismo y garantizar mejoras en la esfera de la seguridad ciudadana (Congreso de la República, 2011).

En consecuencia, los ciudadanos y ciudadanas de Colombia gozan del derecho a la protesta social, lo cual, implica reconocer los parámetros y normativas para ejercer este derecho acorde con los lineamientos de la Ley, sin infracción de esta misma. Si bien, una actitud de diálogo entre el Estado y los ciudadanos constituye un camino ligado hacia las mejoras del bien común, en donde no se dé prevalencia a intereses de terceros, sino a acciones orientadas a generar una sociedad íntegra, formada en el cultivo de la virtud y habituada a obrar en pro del bienestar de los ciudadanos sin aprovechamiento de quienes son vulnerables.

\section{Conclusiones}

Para concluir, el presente texto ha sido una profundización al análisis crítico del deseo, frente a la idea de que los seres humanos son máquinas productoras de deseo propuesta por Félix Guattari y como contraparte se propone el hábito de la virtud para construir una sociedad destinada al bien común, en la medida en que los ciudadanos son autónomos, reconocen al ser humano como fin en sí mismo y entienden cuáles son sus derechos en el marco de la protesta social.

Retornar a la virtud parece una idea diacrónica, mas es todo lo contrario porque gracias a la virtud, el ser humano comprende la necesidad de cultivarse para servir al bien de la comunidad; asimismo, se reconoce como un ser social capaz de intervenir en la esfera de lo político desde un pensamiento crítico capaz de actuar fundamentado desde la noción de que el ser humano no es un medio para alcanzar fines individuales, ni mucho menos para afectar el orden o la seguridad de una comunidad. En el caso de que las acciones humanas sean guiadas solo por el deseo existe un grave peligro, en tanto que al obrar por el ímpetu de las pasiones se está acometiendo en contra del bienestar de la sociedad y se buscan objetos o fines que por el deseo aparentan ser duraderos, mas son efímeros y repercuten de forma negativa sobre los demás.

Es posible afirmar que en el ejercicio de la virtud se requiere de un cultivo constante, un hábito que forje el carácter y encamine el obrar en miras del bien para enaltecer el nombre de la persona desde su libertad y conocimiento de su dignidad. En cambio, el deseo es una constante de búsquedas que nunca se da por satisfecha en la medida que no genera plenitud en lo que a ser persona íntegra se refiere.

Por este motivo, comprender la importancia de actuar en miras del cultivo de la virtud en vez del deseo, es una buena iniciativa para fortalecer el derecho a la protesta social en Colombia, en la medida que la ciudadanía exige mejoras respecto a sus beneficios legales y las autoridades respetan y cumplen su labor en la medida de sus límites. Así mismo, reconocer el derecho a la protesta social como un conjunto de deberes y derechos intrínsecos supone un actuar en beneficio de todos los ciudadanos sin poner en riesgo la seguridad, tanto de quienes participan como de quienes no participan en la protesta. Y, sobre todo, conocer las normas dentro de las cuales cada ciudadano debe cumplir y hacer cumplir permite que terceros no manipulen en beneficio propio este derecho a la protesta pacífica, ni a los protestantes, ni a las autoridades, ni a los jóvenes, ni a quienes no protestan. 
En este sentido, se proponen dos posibles soluciones para que el actuar humano se encamine al perfeccionamiento de la virtud y que esto repercuta de manera favorable sobre las acciones en la protesta social en Colombia. En primera instancia, es imprescindible despertar el interés a la ciudadanía, en especial a los jóvenes, el ejercicio práctico de la virtud para que no guíen su voluntad por el deseo, sino que en un trabajo constante se cultive de manera progresiva la virtud para que desde el deseo no se impongan merecimientos que no correspondan, en un sentido objetivo, al bien común. En segunda instancia, la ciudadanía en tanto que obra por su autonomía ha de cuidar el hecho de no mediatizar, ni ser mediatizado por otros sujetos; si se recuerdan algunas líneas anteriores en el presente texto, para Kant el ser humano ha de ser visto como fin en sí mismo, por esto, se propone fortalecer los lazos de la comunidad en el hecho de encaminar las acciones sin mediatizar al ser humano; de este modo, se construiría una sociedad íntegra, en la cual, prevalezca el respeto y la dignidad humana.

Por lo anterior, si se aplican estas dos posibles soluciones en el marco de la protesta social en Colombia, tanto para quienes protestan o quienes no lo hacen y para las autoridades, es posible que se desencadene la participación del derecho a la protesta social de una manera en la que se conjuguen aspectos como la virtud, la noción del ser humano como fin en sí mismo, la autonomía, entre otros; si se tiene en cuenta esto, entonces, no se deslegitimaría este derecho por causa de la violencia o intereses de terceros. Por lo tanto, es necesario, el conocimiento, el estar informados y, sobre todo, saber cuáles son los derechos y deberes que componen el derecho de la protesta social para que por medio de las acciones se logre una mejoría en lo que atañe el bien de la comunidad.

Dado esto, la concepción maquínica del ser humano que propone Félix Guattari deja de lado el hábito de la virtud para corresponderlo a la satisfacción de intereses que él llama deseos; y, si un ciudadano, en especial un joven, impulsa su vida por el deseo, está llamado a perder la posibilidad de forjar su carácter desde la integralidad, de encaminar sus acciones en el ejercicio constante del perfeccionamiento individual, de obrar en miras del bien propio y de la sociedad y, sobre todo, de honrarse a sí mismo y a sus congéneres por sus acciones. Por esto, el cultivo de la virtud en contra de la satisfacción de los deseos es una propuesta que constituye transformar la percepción de los ciudadanos, en donde la mira se dirija al hábito del ejercicio constante y práctico de la virtud; para que, por el deseo, una persona no encamine su obrar a una satisfacción de intereses y que por esto, transgreda los derechos fundamentales de los otros. Así pues, participar de la protesta social, desde el hábito de la virtud, brindaría al ciudadano visos de que es necesario forjar los valores y laborar progresivamente sobre el perfeccionamiento propio sin mediatizar a los otros para el logro del fin que constituye el derecho a protestar en Colombia. 


\section{Referencias}

Arias, D. (14 de mayo del 2021) ¡Si usted protesta sin el permiso de la autoridad, es un demócrata, no un criminal! Recuperado de https://www.udea.edu. co/wps/portal/udea/web/inicio/udea-noticias/udea-noticia/!ut/p/z0/ fY-xTsNADIZfhSWjdUcbUhgjBqSqQweE2luQlbOoIbEvdw7i8bmUAbG wWP5-fbZsF9zJBcFPfkNjFRwrn0P3ev_wuLntW3_wXdv5vju2d7vN0_ b5xbu9C_8LdQO_z3PoXRhUjL7MnZJmw3GJhI3H8pcuOtFPv9YbUeOBs TT-Oi0cdbV-Y00s9 dbGF4alGEVIWY2KIRQWoBES5YmLQiQYEXAxzRwxAh VYpKaTDhmrLrrykHni9fX0Ec7ftjYtww!!/

Aristóteles. (2003). La Gran Moral. El Cid Editor.

Behrentz, E. (19 de mayo de 2021) Bloquear vías no es ningún derecho. Recuperado de https://www.semana.com/opinion/articulo/bloquear-vias-no-es-ningunderecho/202105/

Calderón Gómez, J. (2006). Sala de máquinas: aproximación al pensamiento de Gilles Deleuze y Félix Guattari. Nómadas: revista Crítica de Ciencias Sociales y Jurídicas. 14(2): 81-96, 2006. Servicio de Publicaciones, Universidad Complutense de Madrid.

Congreso de la República. (24 de junio de 2011) Artículo 353 [Título I] Por la cual se reforma el Código Penal. [Ley 1453 de 2011]

Congreso de la República. (24 de junio de 2011) Artículo 469 [Título I] Por la cual se reforma el Código Penal. [Ley 1453 de 2011]

Congreso de la República. (24 de junio de 2011) Capítulo III del código penal colombiano. Por la cual se reforma el Código Penal. [Ley 1453 de 2011]

Constitución Política de Colombia. Art. 37. 7 de julio de 1991 (Colombia).

Constitución Política de Colombia. Art. 353.7 de julio de 1991 (Colombia

Defensoría del pueblo. (2020). Guía de bolsillo. Derechos, deberes, servicios y rutas de atención en el marco de la protesta social pacífica.

Fundación Ideas para la Paz. (2018) ¿Cómo se rige la protesta pacífica en Colombia? El derecho y la garantía de un derecho fundamental.

Gilson, E. (1973). La Unidad de la Experiencia filosófica. Ediciones Rialp, S. A.

Guattari, F. (2013). Deseo y Revolución: Diálogo con Paolo Bertetto y franco Berardi Bifo 1977. Ediciones Tinta Limón.

Kant, I. (2003). Fundamentación de la metafísica de las costumbres. El Cid Editor.

Kant, I. (2003), Crítica de la Razón Práctica. Editorial La Página S.A 
Kant, I. y Abellán, J. (Ed.). (2013). La paz perpetua. Difusora Larousse - Editorial Tecnos.

Kant, I. (2004). Teoría y praxis. El Cid Editor.

Ley 1453 de 2011. Por la cual se reforma el Código Penal, el Código de Procedimiento Penal, el Código de Infancia y Adolescencia, las reglas sobre extinción de dominio y se dictan otras disposiciones en materia de seguridad. 24 de junio de 2011.

Llano, A. (1999). Humanismo Cívico. Editorial Ariel.

Maldonado, J, Velandia, V. (17 junio 2020) La protesta social: Inequidad, olvido e ignorancia en Colombia. Recuperado de https://www.usergioarboleda.edu. co/sergiointeractivo/lee/la-protesta-social-inequidad-olvido-e-ignoranciacolombia/

Ministerio de agricultura (Febrero 21 del 2013) Jornadas de protesta pueden comprometer normalidad en el suministro de alimentos, previene Minagricultura. Recuperado de http://www.fedearroz.com.co/noticias/ noticiasd2.php?id=1150

Nietzsche, F. (2004). Más allá del bien y del mal. El Cid Editor.

Noticias laborales. (4 mayo 2021) ¿La empresa en donde trabajas está obligada a darte permiso para marchar y protestar? Recuperado de https://www.elempleo.com/ co/noticias/noticias-laborales/la-empresa-en-donde-trabajas-esta-obligadadarte-permiso-para-marchar-y-protestar-6297

Organización de los Estados Americanos. (2019). Protesta y Derechos Humanos. Estándares sobre los derechos involucrados en la protesta social y las obligaciones que deben guiar la protesta social.

Ortega y Gasset, J. (2013). Introducción a una estimativa: ¿qué son los valores? Ediciones Encuentro, S.A.

Ortega \& Gasset, J. (2010). La rebelión de las masas. La Guillotina.

Ortega y Gasset, J. y Pelliciani, L. (2016). Ortega y Gasset: el hombre y la gente. Biblioteca Nueva.

Redacción editorial. El ABC de la protesta ciudadana, un entendimiento entre la libertad y la responsabilidad. Recuperado de https://www.unisabana.edu.co/ portaldenoticias/al-dia/el-abc-de-la-protesta-ciudadana/

Redacción editorial. (Enero 29 del 2013) Sanción penal por obstruir vías públicas no restringe derecho a la protesta. Recuperado de https://www.ambitojuridico. $\mathrm{com} /$ noticias/penal/penal/sancion-penal-por-obstruir-vias-publicas-norestringe-derecho-la-protesta 
Redacción editorial. (Enero 21 del 2016) ¿Cuándo es Delito Protestar en Colombia? Colombian Legal Corporation. Recuperado de https://www.colombialegalcorp. com/blog/delito-protestar-colombia/

Redacción justicia. (08 mayo 2021) El jefe del ente acusador señaló que la ley lo permite y que los jueces tendrán la última palabra. Recuperado de https:// www.eltiempo.com/justicia/investigacion/paro-fiscal-defiende-extincion-dedominio-a-vehiculos-que-bloqueen-vias-586931

Redacción justicia. (14 de septiembre de 2021) Lo que dicen las leyes sobre el derecho a la protesta en Colombia. Recuperado de https://www.eltiempo.com/ amp/justicia/servicios/derecho-a-la-protesta-que-es-y-que-limitacionestiene-618007

Zambrano, M. (1987). Filosofía y poesía. FCE - Fondo de Cultura Económica.

Whinteney, M. (8 de septiembre de 2021) Policías del capitolio advierten sobre posibles actos violentos en las manifestaciones del 18 de septiembre. Recuperado dehttps://www.unisabana.edu.co/portaldenoticias/al-dia/el-abc-de-laprotesta-ciudadana/ 